\title{
BIOCONTROL OF PIGEON TICK ARGAS REFLEXUS (ACARI: ARGASIDAE) BY ENTOMOPATHOGENIC FUNGUS METARHIZIUM ANISOPLIAE (ASCOMYCOTA: HYPOCREALES)
}

\author{
Mosa Tavassoli $^{1 *}$; Seyed Hassan Pourseyed ${ }^{1}$; Abdulghaffar Ownagh ${ }^{2}$ Iraj Bernousi $^{3}$; Karim Mardani $^{4}$ \\ ${ }^{1}$ Department of Pathobiology, Faculty of Veterinary Medicine, Urmia University, Urmia, West Azarbaijan, Iran; ${ }^{2}$ Department of \\ Microbiology, Faculty of Veterinary Medicine, Urmia University, Urmia, West Azarbaijan, Iran; ${ }^{3}$ Department of Genetic and \\ Biometry, Faculty of Agriculture Science, Urmia University, Urmia, West Azarbaijan, Iran; ${ }^{4}$ Department of Food Hygiene and \\ Quality Control, Faculty of Veterinary Medicine, Urmia University, Urmia, West Azarbaijan, Iran.
}

Submitted: November 23, 2010; Returned to authors for corrections: February 03, 2011; Approved: May 16, 2011.

\begin{abstract}
The pigeon tick Argas reflexus is a pathogen-transmitting soft tick that typically feeds on pigeons, but can also attack humans causing local and systemic reactions. Chemical control is made difficult due to environmental contamination and resistance development. As a result, there is much interest in increasing the role of other strategies like biological control. In this study, the efficacy of three strains (V245, 685 and 715C) of entomopathogenic fungus Metarhizium anisopliae for biological control of three life stages of pigeon tick A. reflexus including eggs, larvae, engorged and unfed adults was investigated under laboratory conditions. Five concentrations of different strains of $M$. anisopliae ranging from $10^{3}$ to $10^{7}$ conidia/ml were used. All fungal strains significantly decreased hatchability of $A$. reflexus eggs. Strain V245 was the most effective strain on the mortality of larval stage with nearly $100 \%$ mortality at the lowest concentration $\left(10^{3}\right.$ conidia/ml) at 10 days post-inoculation. The mortality rate of both engorged and unfed adult ticks were also increased significantly exposed to different conidial concentrations compared to the control groups $(P<$ 0.05) making this fungus a potential biological control agent of pigeon tick reducing the use of chemical acaricides.
\end{abstract}

Key words: Argas reflexus, pigeon tick, biological control, entomopathogenic fungus, Metarhizium anisopliae

\section{INTRODUCTION}

Ticks are among the most important vectors of diseases both in humans and animals worldwide (15). Argas reflexus belongs to Argasidae is a soft tick of pigeon (17). It is a specific bloodsucking parasite of pigeon in various parts of Europe and the Middle East which under certain circumstances invades human habitations $(5,10)$ and bites people as a substitute host when pigeons are not available (12) causing not only skin irritations and pathogen transmission (11), but also a 
variety of symptoms corresponding to an IgE-mediated allergy with increasing severity resulting in death $(28,25,30)$.

Control strategies for tick population rely to a large extent on the use of chemical acaricides such as organophosphates, pyrethroids and amidines (22). However, the appearance of pesticide resistant ticks, environmental damage and toxicity of chemical residues to humans are drawbacks to this strategy (16, 18). Recently, entomopathogenic fungi have been considered as very important biocontrol agents for the control of insect pests as they offer a safer alternative for use in integrated pest management than chemical insecticides $(24,1,27)$.

Among entomopathogenic fungi, Metarhizium anisopliae has been extensively studied as a key regulatory organism for biological control of ticks, including Rhipicephalus microplus (6, 2), Rhipicephalus annulatus (20), Ixodes scapularis (13), Rhipicephalus appendiculatus and Amblyomma variegatum (14). Previous studies demonstrated that the entomopathogenic fungi are more environmentally friendly agents which can be used as safer and more reliable alternatives for use in controlling ticks than chemical insecticides $(8,19)$.

In the present study, the acaricidal effect of three strains of M. anisopliae (one from UK, one from Finland and one from Iran) for the biological control of three life stages of pigeon tick $A$. reflexus including eggs, larvae, engorged and unfed adults has been evaluated.

\section{MATERIALS AND METHODS}

\section{Fungus Strains}

Three strains of $M$. anisopliae were used for the following bioassays, including strain 685 isolated from Ixodes ricinus in UK, strain V245, isolated from Hayfield soil in Finland and strain $715 \mathrm{C}$ isolated from a locust in Iran, were used in this study. The first two strains were part of the fungal culture collection at the University of Wales Swansea, UK while the Iranian strain was held at the University of Tehran, Iran.

Fungal virulence was maintained by passaging twice through $A$. reflexus ticks before being reproduced on PDA (potato dextrose agar; E. Merck, Germany) in Petri dishes (90 $\mathrm{mm} \times 15 \mathrm{~mm}$ ) in a dark incubator at $25^{\circ} \mathrm{C}$ for 2 weeks. Harvested conidia were suspended in sterilized distilled water (dH2O) containing $0.05 \%$ Tween 80 , and later stored at $4{ }^{\circ} \mathrm{C}$. The density of conidial suspension was adjusted to $10^{3}, 10^{4}$, $10^{5}, 10^{6}$ and $10^{7}$ conidia/ml with a Neubauer haemocytometer as described by Butt and Goettel (4). Percentage of viable conidia of each strain was determined on PDA prior to bioassays using the method of Goettel and Inglis (9).

\section{Ticks}

The $A$. reflexus ticks are active during the night and spend the daytime hidden in cracks and crevices of pigeon nests. Therefore, nestlings, adult pigeons and crevices of the walls of buildings with the gable roof where pigeons were living in the near vicinity of human beings in Urmia City, West Azarbaijan of Iran were examined for the presence of ticks. Different developmental stages of $A$. reflexus were collected from each naturally infested site and sent to the Parasitology Laboratory of the Faculty of Veterinary Medicine in the Urmia University for identification and sex determination using morphological characteristics $(3,29)$. Collected ticks were then immersed in $70 \%$ ethanol for 3 seconds in vertical laminar flow chamber and dried on sterile filter paper (26). Unfed and engorged female ticks were used for experiments without considering their age.

Some adult engorged female ticks were maintained in cotton-capped glass tubes containing filter paper moistened with sterile distilled water. The tubes were then placed in a desiccator at room temperature $\left(22-25{ }^{\circ} \mathrm{C}\right)$ with $80 \%$ relative humidity $(\mathrm{RH})$. After oviposition, some eggs were transferred into different tubes and kept until larval emergence. Upon hatching, live larvae were stored in a sterile tube until fungal treatment.

\section{Bioassay Procedures}

Three virulence assays of fungal strains were conducted against eggs, larvae and adult ticks of $A$. reflexus using varying 
conidia concentrations. Conidia concentrations for each developmental stage were chosen according to our previous biocontrol study on another important argasid tick called Argas persicus (21). Randomly selected specimens were submerged for $5 \mathrm{~s}$ in suspensions ranging from $10^{3}$ to $10^{7}$ conidia $/ \mathrm{ml}$ prepared in $0.05 \%$ aqueous Tween 80 in the bioassays as indicated. For control treatment, the specimens were only immersed in sterile $\mathrm{dH} 2 \mathrm{O}$. Trials for each concentration and control group were performed in three replicates. Treated specimens were kept in Petri dishes, on a moist filter paper soaked with sterile $\mathrm{dH} 2 \mathrm{O}$ and stored in a dark incubator at 25 ${ }^{\circ} \mathrm{C}$ with $80 \%$ RH. Treated groups were evaluated every $2-3$ days and fungal infection was confirmed upon fungal sporulation by microscopic examination. Fungal virulence was further evaluated by $\mathrm{LC}_{50}$ estimation in adult susceptibility bioassay.

Egg bioassay: In order to evaluate the effect of fungal strains on egg hatchability, randomly selected eggs without considering their age were inoculated with the suspension of $1 \times 10^{3}$ conidia $/ \mathrm{ml}$. A total of 600 eggs (50 per Petri dish) were used. Larval emergence was recorded in both treatment and control groups at $48 \mathrm{~h}$ intervals over a 12-day period postinoculation until no more hatching was observed.

Larval bioassay: The bioassay was designed to assess the lethal effect of $M$. anisopliae on the larval stage of $A$. reflexus. A total of 1050 larvae (50 per Petri dish) were infected with two different concentrations $\left(10^{3}\right.$ and $10^{4}$ conidia/ml $)$ of three different strains of $M$. anisopliae. The number of dead larvae was recorded at 2, 4, 6, 8, 10, and 12 days post-inoculation (DPI) in both treatment and control groups.

Adult bioassay: Because of the importance of female ticks in spreading the diseases by laying eggs, only adult females were selected for use in our experiments. A total of 300 ticks ( 5 per Petri dish) were used in two separate tests by immersing engorged and unfed adult females in conidial suspensions of $10^{5}, 10^{6}$ and $10^{7}$ conidia $/ \mathrm{ml}$. Petri dishes were observed for three weeks at $3,6,9,12,15,18$, and 21 DPI to detect dead ticks and fungal growth.

\section{Determining Infection}

Seven days after death, fungal hyphae started to emerge and sporulate and dead larvae and adult ticks appeared swollen with greenish areas on their body and legs. Mortality due to $M$. anisopliae was then confirmed by microscopic examination of hyphae and spores on the surface of fungal treatment specimens.

\section{Data Analysis}

Data analysis was performed using general leaner model and repeated measure analysis (three-factor mixed design) using Statistical Package for the Social Sciences (SPSS, Version 17, Chicago). Values of $P<0.05$ were considered significant.The virulence data were examined by Probit analysis to obtain the $\mathrm{LC}_{50}$ values with $95 \%$ confidence limit using MINITAB (Version 14, State college, Pennsylvania).

\section{RESULTS}

\section{Egg Bioassay}

Treated eggs were shriveled and turned to a reddish/purple color before sporulation was observed on their surfaces. All three strains of $M$. anisopliae with the conidia viability of more than $96 \%$ significantly decreased hatchability of $A$. reflexus eggs compared to the control group $(P<0.05)$. Only $13.3 \%$ of the eggs infected with V245 strain were hatched after two weeks, while the hatchability rate was $16 \%$ and $17.3 \%$ for the eggs infected with strains $715 \mathrm{C}$ and 685 respectively. In contrast, the hatching rate in the control group was $87.3 \%$ (Fig. $1)$.

\section{Larval Bioassay}

The results showed that all three strains of fungi examined were effective on the larvae at 4 DPI $(P<0.05)$. At 6 DPI strain V245 had the highest effect on larval stage with a mortality rate more than $75 \%$ for two conidial concentrations 
which have been used. All strains caused more than $80 \%$ mortality at 10 DPI and almost $100 \%$ mortality at 12 DPI in the larvae examined (Fig. 2). It was observed that an increase in the mortality rate of larvae was proportional to the concentration of conidia used, i.e., the greater the concentration of conidia, the higher the percentage mortality of larvae.

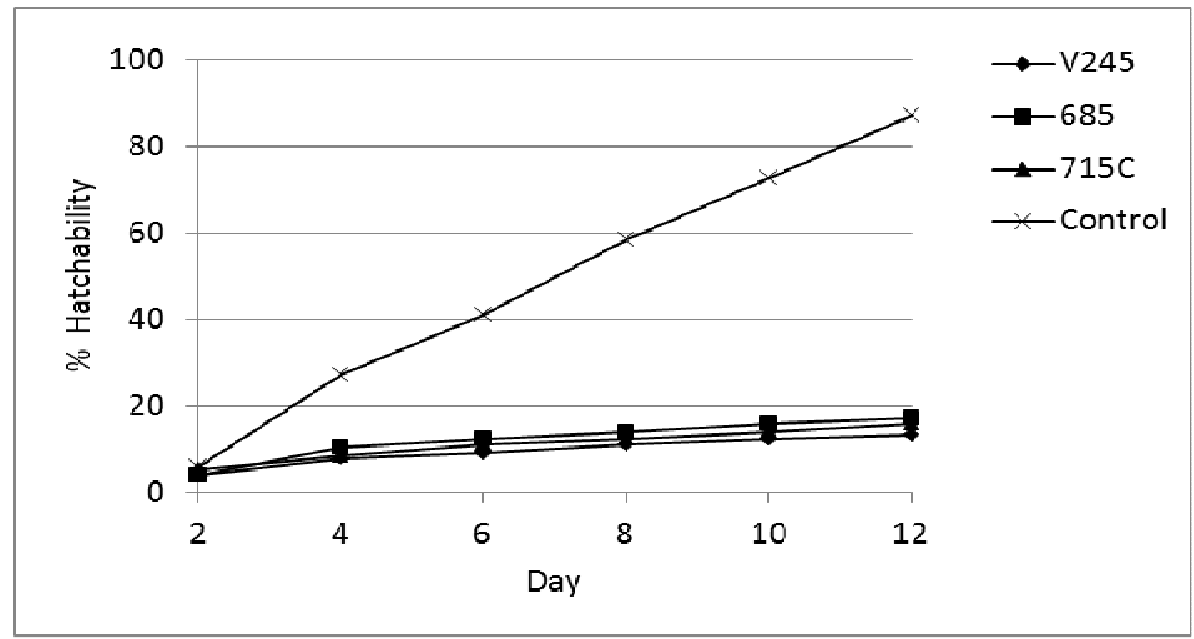

Figure 1. Hatchability of $A$. reflexus eggs exposed to conidial concentration of $10^{3}$ conidia/ml of $M$. anisopliae strains.
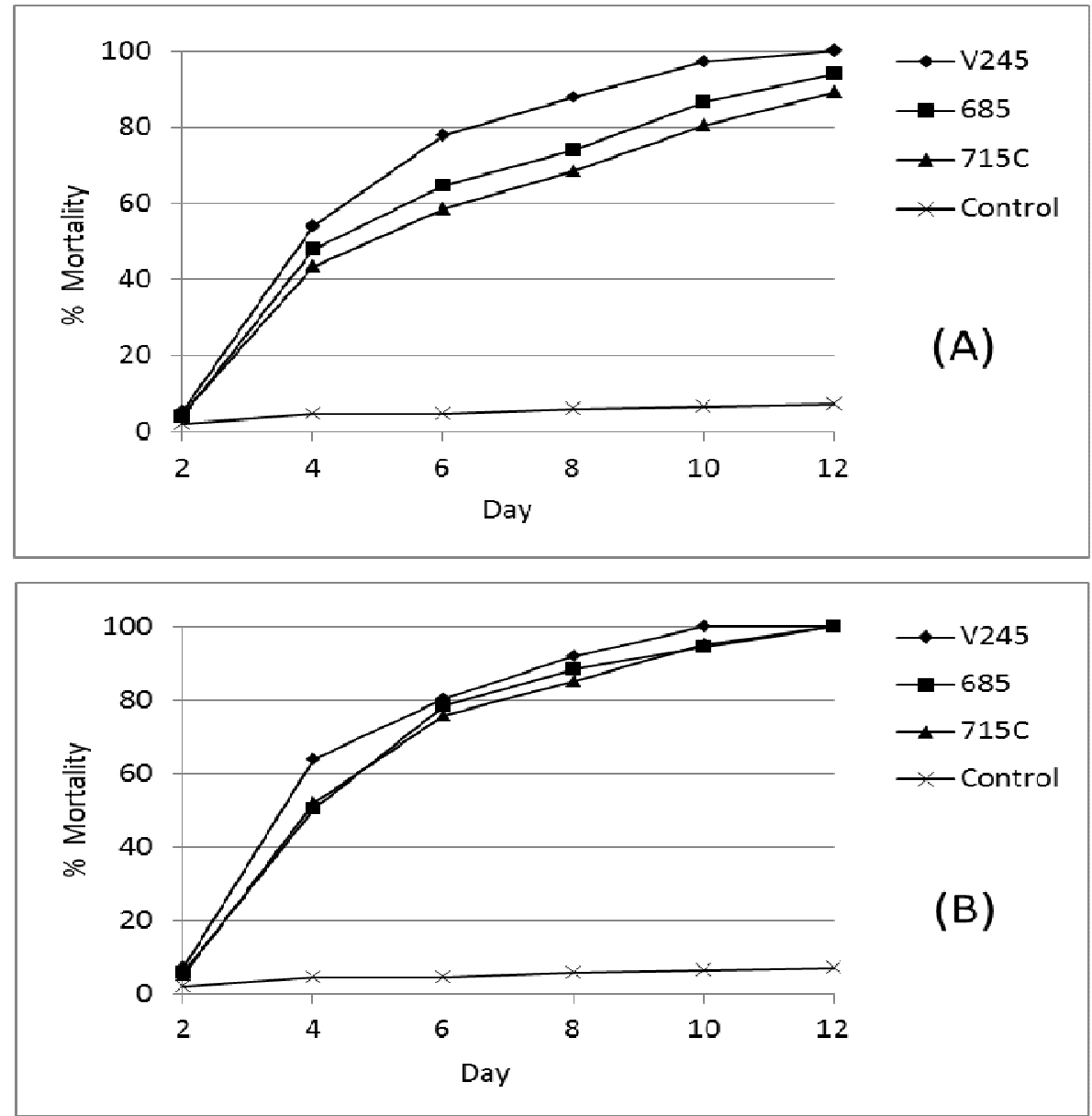

Figure 2. Mortality of $A$. reflexus larvae exposed to two conidia concentrations (A: $10^{3}$ conidia/ml and B: $10^{4}$ conidia/ml) of $M$. anisopliae strains. 


\section{Adult Bioassay}

All strains of $M$. anisopliae examined in this study increased the mortality rate in the engorged ticks significantly $(P<0.05)$ at 9 DPI comparing to the control group (Fig. 3). The infected engorged females appeared swollen and have been completely covered with fungal hyphae. Strain V245 was the most effective strain with $\mathrm{LC}_{50}$ value of $2.7 \times 10^{4}$ conidia/ml at $15 \mathrm{DPI}$ followed by $715 \mathrm{C}$ with $\mathrm{LC}_{50}$ value of $4 \times 10^{4}$ conidia/ml at 15 DPI (Table
1).

Unfed female ticks showed a lower susceptibility than engorged female ticks to different fungal strains (Fig. 4). The mortality rate significantly increased at 12 DPI $(P<0.05)$. The results revealed that strain V245 was the most effective strain on unfed ticks same as results obtained for engorged ticks. The $\mathrm{LC}_{50}$ values for all strains have been calculated at 12 and 15 DPI (Table $1)$.

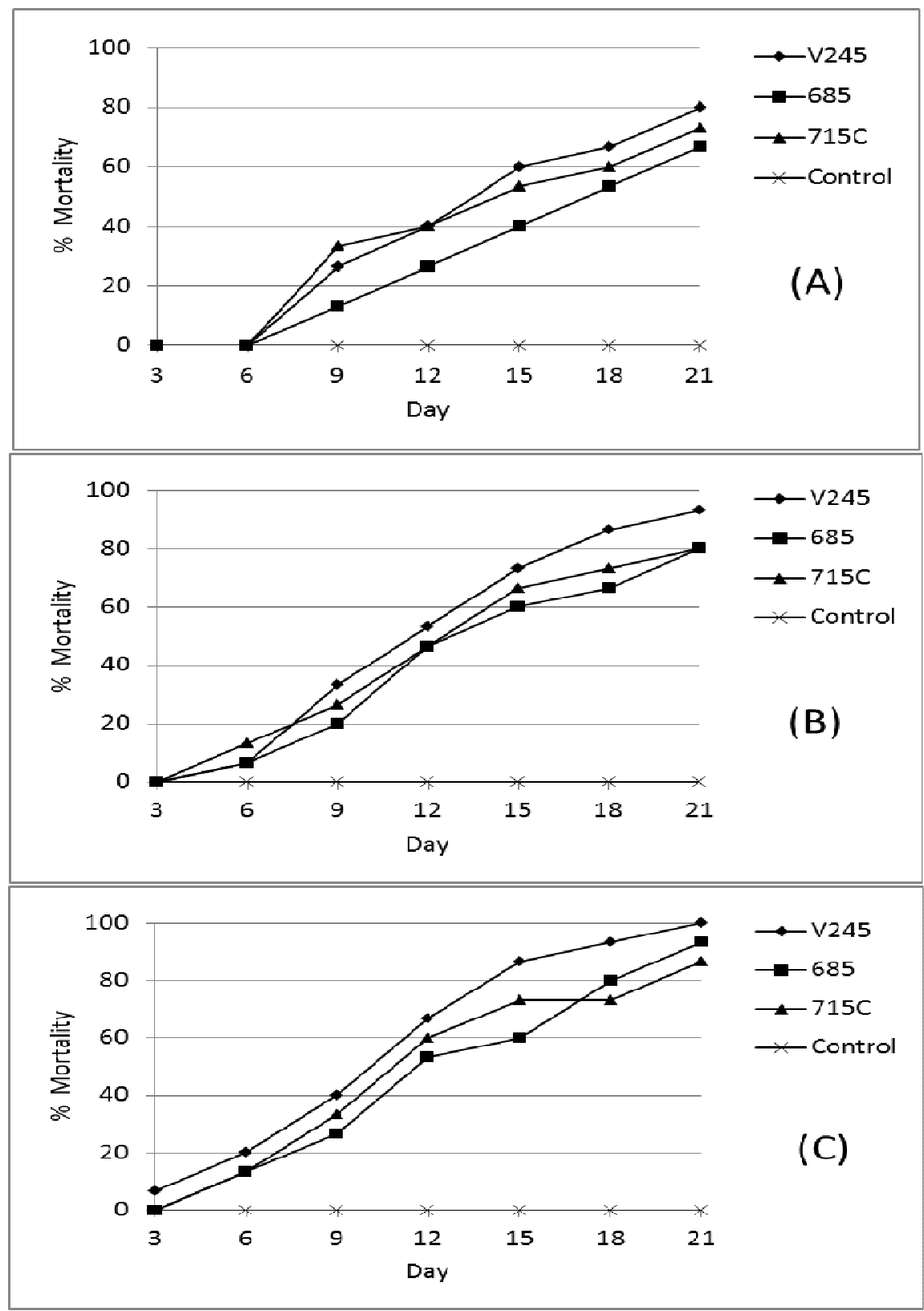

Figure 3. Mortality of $A$. reflexus engorged adult females exposed to three conidia concentrations (A: $10^{5}$ conidia/ml, B: $10^{6}$ conidia/ml and $\mathrm{C}: 10^{7}$ conidia $\left./ \mathrm{ml}\right)$ of $M$. anisopliae strains. 


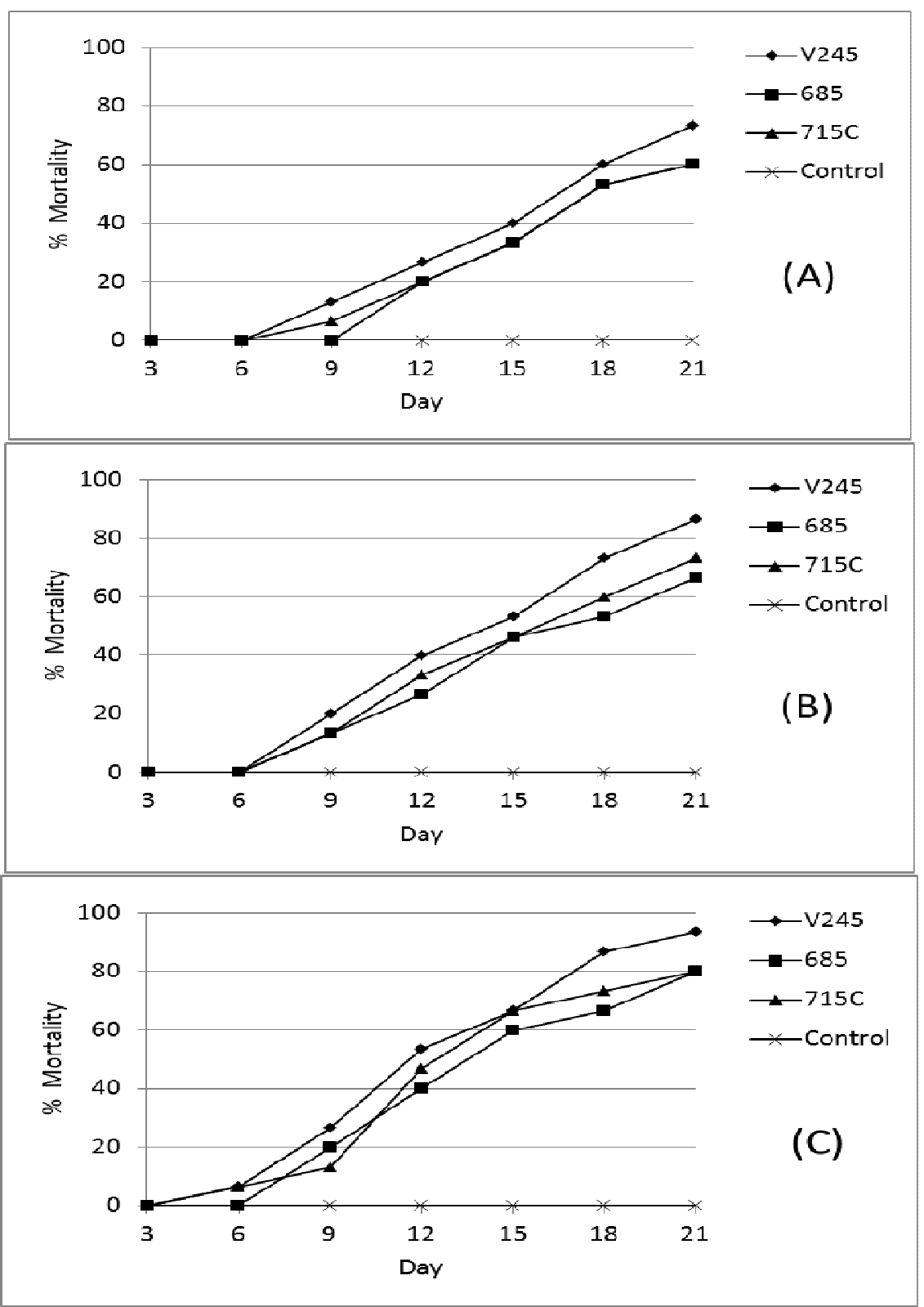

Figure 4. Mortality of $A$. reflexus unfed adult females exposed to different conidia concentrations (A: $10^{5}$ conidia/ml, B: $10^{6}$ conidia/ml and $\mathrm{C}: 10^{7}$ conidia $/ \mathrm{ml}$ ) of $M$. anisopliae strains.

Table 1. Mean lethal concentrations $\left(\mathrm{LC}_{50}\right)$ of $M$. anisopliae strains against $A$. reflexus engorged and unfed adult females.

\begin{tabular}{cccc}
\hline \multirow{2}{*}{$\begin{array}{c}\text { Fungal } \\
\text { strain }\end{array}$} & \multirow{2}{*}{ Day } & \multicolumn{2}{c}{ LC $_{\mathbf{5 0}}(\mathbf{9 5 \%}$ confidence interval) } \\
\cline { 2 - 4 } \multirow{2}{*}{$\mathrm{V} 245$} & 12 & $5.5 \times 10^{5}\left(4.0 \times 10^{4}\right.$ to $\left.7.5 \times 10^{6}\right)$ & $5.5 \times 10^{6}\left(2.1 \times 10^{5}\right.$ to $\left.1.4 \times 10^{8}\right)$ \\
& 15 & $2.7 \times 10^{4}\left(3.1 \times 10^{2}\right.$ to $\left.2.4 \times 10^{6}\right)$ & $5.5 \times 10^{5}\left(4.0 \times 10^{4}\right.$ to $\left.7.5 \times 10^{6}\right)$ \\
\hline \multirow{2}{*}{685} & 12 & $3.8 \times 10^{6}\left(1.9 \times 10^{5}\right.$ to $\left.7.6 \times 10^{7}\right)$ & $8.4 \times 10^{7}\left(4.4 \times 10^{4}\right.$ to $\left.1.6 \times 10^{11}\right)$ \\
& 15 & $4.6 \times 10^{5}\left(1.2 \times 10^{4}\right.$ to $\left.1.7 \times 10^{7}\right)$ & $1.7 \times 10^{6}\left(1.3 \times 10^{5}\right.$ to $\left.2.4 \times 10^{7}\right)$ \\
\hline \multirow{2}{*}{$715 \mathrm{C}$} & 12 & $1.2 \times 10^{6}\left(4.3 \times 10^{4}\right.$ to $\left.3.8 \times 10^{7}\right)$ & $1.5 \times 10^{7}\left(2.8 \times 10^{5}\right.$ to $\left.8.6 \times 10^{8}\right)$ \\
& 15 & $4.0 \times 10^{4}\left(7.9 \times 10\right.$ to $\left.2.0 \times 10^{7}\right)$ & $1.1 \times 10^{6}\left(1.5 \times 10^{5}\right.$ to $\left.8.7 \times 10^{6}\right)$ \\
\hline
\end{tabular}




\section{DISCUSSION}

M. anisopliae and Beauveria bassiana are the most promising entomopathogenic fungi which some strains of them are already commercially available for the control of some pests. On the other hand, the safety of these fungi towards human and the environment is clearly an important criterion for consideration $(8,19)$. Development of effective formulations (concentration of fungi conidia and exposure time) is critical for biological control of ticks (23). A. reflexus is the most important ectoparasite of pigeon that can also involve human health by inducing anaphylactic reactions in human, and as vector, can transmit some pathogens. The tick possesses a range of biological features that make it difficult to eradicate.

The results of this study indicated that different developmental stages of $A$. reflexus had a wide spectrum of variation in their susceptibility to three strains of $M$. anisopliae. The mortality percentages and the $\mathrm{LC}_{50}$ values showed that strain V245 was more effective than other two strains against different developmental stages of $A$. reflexus, while strains 685 and $715 \mathrm{C}$ had almost similar effect. In the present study the highest mortality rate (85-100\%) of both engorged and unfed A. reflexus females caused by $M$. anisopliae strains was at 18 to 21 DPI. However, in studies by Gindin et al. (7) and PiraliKheirabadi et al. (20), the highest mortality of Rhipicephalus annulatus females caused by M. anisopliae was $90-100 \%$ at 7 to 10 days DPI indicating the variation in the effect of $M$. anisopliae on different species of the ticks.

The application of $M$. anisopliae for biological control of different species of animal ticks has been evaluated and it has been found that this fungus has considerable potential as a microbial control agent for the management of animal ticks $(14,31)$. Kaaya et al. (14) also showed the pathogenicity of entomogenous fungi to different developmental stages of Rhipicephalus appendiculatus under field conditions. Tavassoli et al. (27) and Pourseyed et al. (21) reported that the pathogenicity of three strains of $M$. anisopliae on different life stages of Dermanyssus gallinae and Argas persicus in the laboratory was concentration and time dependent, which was in agreement with the results obtained in the present study.

In conclusion, the present study revealed that under laboratory conditions different strains of $M$. anisopliae in different concentrations had high pathogenicity against different life stages of pigeon tick $A$. reflexus. The estimated $\mathrm{LC}_{50}$ values for all three strains also showed that they had promising potential as biocontrol agents of pigeon tick. Therefore, further investigations are necessary to validate the methods for possible use of these strains under field conditions.

\section{ACKNOWLEDGEMENTS}

Authors would like to sincerely thank the members of the Faculty of Veterinary Medicine and Urmia University Research Council for the approval and financial support of this research and Mr. A. Aghapour for his technical assistance.

\section{REFERENCES}

1. Abolins, S.; Thind, B.; Jackson, V.; Luke, B.; Moore, D.; Wall, R.; Taylor, M.A. (2007). Control of sheep scab mite Psoroptes ovis in vivo and in vitro using fungal pathogens. Vet. Parasitol. 148, 310-317.

2. Alonso-Diaz, M.A.; Garcia, L.; Galindo-Velasco, E.; Lezama-Gutierrez, R.; Angel-Sahagun, C.A.; Rodriguez-Vivas, R.I.; Fragoso-Sanchez, H. (2007). Evaluation of Metarhizium anisopliae (Hyphomycetes) for the control of Boophilus microplus (Acari: Ixodidae) on naturally infested cattle in the Mexican tropics. Vet. Parasitol. 147, 336-340.

3. Buczek, A. (1993). Morphological variability of Argas (A.) reflexus (Fabricius, 1794) (Acari: Ixodida: Argasidae) females and males from a Silesian population. Z. Angew. Zool. 4, 409-419.

4. Butt, T.M.; Goettel, M. (2000). Bioassays of entomogenous fungi. In: Navon, A., Ascher, K.R.S. (eds) Bioassays of entomopathogenic microbes and nematodes. CAB International, Wallingford, p. 141-195.

5. Dautel, H.; Kahl, O.; Scheurer, S.; Kntille, W. (1994). Seasonal activities of the pigeon tick Argas reflexus (Acari: Argasidae) in Berlin, Germany. Fol. Parasitol. 41, 155-160.

6. Frazzon, A.P.; da Silva Vaz Junior, I.; Masuda, A.; Schrank, A.; Vainstein, M.H. (2000). In vitro assessment of Metarhizium anisopliae isolates to control the cattle tick Boophilus microplus. Vet. Parasitol. 94, 117-125.

7. Gindin, G.; Samish, M.; Zangi, G.; Mishoutchenko, A.; Glazer, I. (2002). 
The susceptibility of different species and stages of tick to entomopathogenic fungi. Exp. Appl. Acarol. 28, 283-288.

8. Goettel, M.S.; Hajek, A.E.; Quimby, P.C. (2000). Evaluation of nontarget effects of pathogens used for management of arthropods. In: Wajnberg, E., Scott, J.K., Quimby, P.C. (eds) Evaluating indirect ecological effects of biological control. CABI Publishing, Wallingford, p. 81-89.

9. Goettel, M.S.; Inglis, G.D. (1997). Fungi: hyphomycetes. In: Lacey, L. (ed) Manual of techniques in insect pathology. Academic, San Diego, CA, p. 213-249.

10. Haag-Wackernagel, D.; Bircher, A.J. (2010). Ectoparasites from feral pigeons affecting humans. Dermatology. 220 (1), 82-92.

11. Haag-Wackernagel, D.; Moch, H. (2004). Health hazards posed by feral pigeons. J. Infection. 48, 307-313.

12. Hilger, C.; Bessot, J.C.; Hutt, N.; Grigioni, F.; De Blay, F.; Pauli, G.; Hentges, F. (2005). IgE-mediated anaphylaxis caused by bites of the pigeon tick Argas reflexus: cloning and expression of the major allergen Arg r 1. J. Allergy. Clin. Immunol. 115, 617-622.

13. Hornbostel, V.L.; Ostfeld, R.S.; Benjamin, M.A. (2005). Effectiveness of Metarhizium anisopliae (Deuteromycetes) against Ixodes scapularis (Acari: Ixodidae) engorging on Peromnyscus leucopus. J. Vector. Ecol. 30, 91-101.

14. Kaaya, G.P.; Mwangi, E.N.; Ouna, E.A. (1996). Prospects for biological control of livestock ticks, Rhipicephalus appendiculatus and Amblyomma variegatum, using the entomogenous fungi Beauveria bassiana and Metarhizium anisopliae. J. Invertebr. Pathol. 67, 15-20.

15. Kaufman, W.R. (2010). Ticks: Physiological aspects with implications for pathogen transmission. Ticks. Tick-borne. Dis. 1, 11-22.

16. Kirkland, B.H.; Cho, E.M.; Keyhani, O.N. (2004). Differential susceptibility of Amblyomma maculatum and Amblyomma americanum (Acari: Ixodidea) to the entomopathogenic fungi Beauveria bassiana and Metarhizium anisopliae. Biol. Control. 31, 414-421.

17. Kleine-Tebbe, J.; Heinatz, A.; Graser, I.; Dautel, H.; Hansen, G.N.; Kespohl, S.; Rihs, H.P.; Raulf-Heimsoth, M.; Vater, G.; Rytter, M.; Haustein, U.F. (2006). Bites of the European pigeon tick (Argas reflexus): Risk of IgE-mediated sensitizations and anaphylactic reactions. J. Allergy. Clin. Immunol. 117, 190-195.

18. Ostfeld, R.S.; Price, A.; Hornbostel, V.L.; Benjamin, A.B.; Keesing, F. (2006). Controlling ticks and tick-borne zoonoses with biological and chemical agents. Bioscience. 5, 383-394.

19. Pell, J.K.; Eilenberg, J.; Hajek, A.E.; Steinkraus, D.C. (2001). Biology, ecology and pest management potential of Entomophthorales. In: Butt, T.M., Jackson, C., Magan, N. (eds) Fungi as biocontrol agents: progress, problems and potential. CAB International, Wallingford, $\mathrm{p}$.
71-153.

20. Pirali-Kheirabadi, K.; Haddadzadeh, H.; Razzaghi-Abyaneh, M.; Bokaie, S.; Zare, R.; Ghazavi, M.; Shams-Ghahfarokhi, M. (2007). Biological control of Rhipicephalus (Boophilus) annulatus by different strains of Metarhizium anisopliae, Beauveria bassiana and Lecanicillium psalliotae fungi. Parasitol. Res. 100, 1297-1302.

21. Pourseyed, S.H.; Tavassoli, M.; Bernousi, I.; Mardani, K. (2010). Metarhizium anisopliae (Ascomycota: Hypocreales): An effective alternative to chemical acaricides against different developmental stages of fowl tick Argas persicus (Acari: Argasidae). Vet. Parasitol. 172, 305310 .

22. Rodriguez-Vivas, R.I.; Alonso-Dı'az, M.A.; Rodrı'guez-Arevalo, F.; Fragoso-Sanchez, H.; Santamaria, V.M.; Rosario-Cruz, R. (2006). Prevalence and potential risk factors for organophosphate and pyrethroid resistance in Boophilus microplus ticks on cattle ranches from the state of Yucatan, Mexico. Vet. Parasitol. 136, 335-342.

23. Samish, M.; Ginsberg, H.; Glazer, I. (2004). Biological control of ticks. Parasitology. 129 Suppl: S389-403.

24. Shah, P.A.; Pell, J.K. (2001). Entomopathogenic fungi as biological control agents. Appl. Microbiol. Biotechnol. 61, 413-423.

25. Spiewak, R.; Lundberg, M.; Johansson, G.; Buczek, A. (2006). Allergy to pigeon tick (Argas reflexus) in Upper Silesia, Poland. Ann. Agric. Environ. Med. 13, 107-112.

26. Tavassoli, M.; Ownag, A.; Meamari, R.; Rahmani, S.; Mardani, K.; Butt, T. (2009). Laboratory evaluation of three strains of the entomopathogenic fungus Metrahizium anisopliae for controlling Hyalomma anatolicum anatolicum and Haemaphysalis punctata. Int. J. Vet. Res. 3, 11-15.

27. Tavassoli, M.; Ownag, A.; Pourseyed, S.H.; Mardani, K. (2008). Laboratory evaluation of three strains of the entomopathogenic fungus Metarhizium anisopliae for controlling Dermanyssus gallinae. Avian. Pathol. 37, 259-263.

28. Trautmann, A.; Amschler, A.; Schultz, K.D.; Brecker, E.B.; Klein, C.E. (1995). Anaphylactic reactions caused by pigeon ticks. Dermatosen. 43, 215-218.

29. Wall, R.; Shearer, D. (1997). Veterinary Entomology, 1st edn. Chapman and Hall International Thompson Publisher Company, London.

30. Weckesser, S.; Hilger, C.; Lentz, D.; Jakob, T. (2010). Anaphylactic reactions to bites of the pigeon tick Argas reflexus. Eur. J. Dermatol. 20 (2), 244-5.

31. Zhioua, E.; Browning, M.; Johnson, P.W.; Ginsberg, H.S.; Lebrun, R.A. (1997). Pathogenicity of the entomopathogenic fungus Metarhizium anisopliae (Deuteromycetes) to Ixodes scapularis (Acari: Ixodidae). J. Parasitol. 83, 815-818. 